\title{
Knowledge and Practices about HIV/AIDS Among the Commercial Sex Workers in Bangladesh
}

\author{
Mahbubur Rahman ${ }^{1}$, M. Wali-ul Islam ${ }^{2}$, and Tsuguya Fukui ${ }^{1}$
}

\begin{abstract}
A survey on knowledge and practices of 228 Bangladeshi commercial sex workers (CSWs) concerning AIDS was conducted in the largest brothel in Narayangonj, $20 \mathrm{~km}$ from the capital Dhaka in September through December, 1993. Only $18 \%$ of the respondents heard about AIDS and $8 \%$ knew about its propensity to sexual transmission. AIDS was believed to be curable by $5 \%$ of the total respondents. None were regular condom users, but $8 \%$ said condom use could prevent HIV infection.

Vigorous AIDS awareness campaigns for the CSWS and their clients, leading to regular condom use, is necessary to prevent an explosive epidemic in Bangladesh.

$J$ Epidemiol, $1998 ; 8: 181-183$.
\end{abstract}

HIV, AIDS, CSWs, brothels and condom

HIV/AIDS has been gradually invading Bangladesh. Bangladesh is currently in the early phases of the epidemic with only $77 \mathrm{HIV}$ carriers identified ${ }^{1}$. It is obvious that HIV/AIDS is not a major health threat in Bangladesh at the present time. World Health Organization (W.H.O.), however, estimates that Bangladesh could possibly have 20,000 HIV carriers as of January $1996^{2}$. This figure could rise up to $147,000-703,000$ by the year $2000^{3}$. Officially, HIV carriers have been found among the commercial sex workers (CSWs) and drug addicts but not among the professional blood donors ${ }^{1}$. Reported figures could be the result of underestimation because of an inappropriate surveillance system. Thousands of Bangladeshi travel to countries with known high HIV prevalence like India and Thailand, for trade, tour, treatment, recreational and educational reasons. As many as 190,000 Bangladeshi traveled to various middle east countries, Malaysia, Singapore and South Korea for obtaining jobs in June, 1996 through April, $1997^{4}$ ). It is not unrealistic to suspect that some of these travelers visit brothels or practice unsafe sex abroad. In fact, in Asia where heterosexual transmission of HIV is the most common means of infection ${ }^{5}$, CSWs are important vehicles for it ${ }^{*}$. Since $34 \%$ of the total
HIV carriers are found among the emigrant workers ${ }^{1}$, it is likely that some of the frequent travelers and repatriate workers transmit HIV to the CSWs in Bangladesh. To obviate an explosive HIV transmission in Bangladesh it is mandatory to raise AIDS awareness among the CSWs.

This survey was conducted to obtain baseline data on sociodemographics and knowledge about AIDS among the CSWs. We expect that this data would enable us to formulate the most appropriate AIDS awareness program for the CSWs and their clients in Bangladesh.

\section{METHODS}

\section{Setting}

Bangladesh is a south Asian country with the Bay of Bengal on the south and bordered by India on three sides and Myanmar on the south east. There are legal brothels in some parts of the country.

The study was conducted at the largest brothel in Narayangonj, $20 \mathrm{~km}$ from the capital, Dhaka.

Study subjects

Received June 21, 1997 ; accepted April 21, 1998.

'Department of General Medicine and Clinical Epidemiology, Kyoto University School of Medicine, Kyoto, Japan.

${ }^{2}$ Bangladesh Health Information Dissemination Agency (BHIDA), Dhaka, Bangladesh.

Address for correspondence : Mahbubur Rahman, Department of General Medicine and Clinical Epidemiology, Kyoto University School of Medicine 54 Kawahara-cho, Shogoin, Sakyo-ku, Kyoto, 606-8507 Japan. 
Subjects were 228 CSWs randomly selected from 2000 $2500 \mathrm{CSWs}$ during the period of September through December, 1993. Since there was no available list of CSWs, every tenth of the CSWs were approached for interviewing. After obtaining informed consent, interviews were conducted for about 20-25 minutes by trained interviewers. A three-day training program was arranged for these interviewers to maintain coherency. The interview procedures were observed by one of the authors to verify standardized interviewing. As most of the CSWs were illiterate, a group of local young people and CSWs were recruited to facilitate the interview process. The whole interview was accomplished in a relaxed atmosphere after initial inquiry about their socioeconomic condition.

\section{Survey Instruments}

A survey questionnaire on demographic information, AIDS related knowledge, knowledge and practice about condoms, curability of AIDS, and high risk behaviors, was developed using the language of Bangla (mother language of Bangladeshi people) considering sociocultural aspects of the Bangladeshi population. The questionnaire was proved to be valid by the pretest done among the $20 \mathrm{CSWs}$. Both open and closed-ended questions were included in the final draft.

\section{RESULTS}

\section{Sociodemographic status}

The sociodemographics of the CSWs are shown in Table 1. Almost all respondents were Muslim and $71 \%$ were married. The mean age was 20 years with very short educational background. They had worked in the brothel on the average for 2.5 years.

\section{Knowledge and practices about HIV/ AIDS (Table 2)}

Only $18 \%$ of the respondents had heard about AIDS. Regarding transmission of AIDS, $8 \%$ cited sexual transmission and 5\% casual contact (i.e., sharing food, clothes, and bed) with the HIV infected persons. When asked about consequences of AIDS, $13 \%$ said that AIDS leads to inevitable death and 5\% thought that AIDS is curable. Regarding knowledge on how to protect themselves from AIDS, only $8 \%$ said that using condom is effective.

Of the respondents, $61 \%$ had never heard about sexually transmitted diseases (STDs), 13\% had some knowledge about AIDS, syphilis and gonorrhea, $5 \%$ about syphilis and gonorrhea, $11 \%$ about syphilis only and $3 \%$ about gonorrhea only.

Eighty-nine percent of the respondents said that a condom is a rubber material while $11 \%$ considered it a birth control material. None of the CSWs were regular users of condom.

After receiving explanations on HIV/AIDS $97 \%$ of the respondents said that condoms would be widely used by enhancing AIDS awareness among the CSWs and their clients
Table 1. Sociodemographic status of the CSWs $(\mathrm{N}=228)$

\begin{tabular}{ll}
\hline Characteristics & \\
\hline Mean age (range) & 20 yrs. (15-35) \\
Married & $71 \%$ \\
Religion & \\
-Muslim & $99 \%$ \\
-Hindu & $1 \%$ \\
Mean schooling years (range) & $1.25(0-8)$ \\
District of origin & Barisal(28\%), \\
& Mymensingh(22\%), \\
& Comilla $(15 \%)$, \\
& Noakhali(11\%), \\
& Others $(24 \%)$ \\
Mean duration of stay in the & 2.5 yrs. $(25$ days-20 yrs.) \\
brothel (range) & \\
Nature of entry into the brothel & \\
-Joined voluntarily due to poverty & $83 \%$ \\
-Exploited by somebody & $13 \%$ \\
-No response & $4 \%$
\end{tabular}

Table 2. Knowledge and practices about AIDS and condom

$(\mathrm{N}=228)$

\begin{tabular}{lr}
\hline Categories & \\
\hline Heard about AIDS & $18 \%$ \\
Know about sexual transmission & $8 \%$ \\
AIDS mean death & $13 \%$ \\
AIDS is curable & $5 \%$ \\
Condom can prevent AIDS & $8 \%$ \\
Condom is only rubber material & $89 \%$ \\
Condom is used for birth control & $11 \%$ \\
Know some of the STDs & $39 \%$ \\
Regular condom users & $\mathrm{Nil}$ \\
Anal sex without condom & $20 \%$ \\
Oral sex without condom & $5 \%$ \\
\hline
\end{tabular}

using posters, flipcharts, and leaflets showing the transmission and consequence of AIDS.

About $20 \%$ of the CSWs had had an experience of anal sex, while $5 \%$ had oral sex without using condoms.

\section{DISCUSSION}

The overall preparedness for HIV prevention is poor in Bangladesh. There is no screening system at blood donation. There is neither periodic medical check-up program nor STDs treatment service for CSWs at brothels or for floating sex workers. AIDS awareness in the general public is very low. Although this study was done about 4 years ago but the results 
of the other two studies, conducted in $1996^{7}$ and $1997^{8)}$ among the professional blood donors and overseas job seekers respectively, revealed no significant change in AIDS awareness. Twenty -six percent of the overseas job seekers and $10 \%$ of the professional blood donors had some sorts of AIDS awareness, reported in these studies.

The National AIDS Committee (NAC) was established in Bangladesh in 1985. Their HIV prevention activities, however, seem to be scattered and limited. Faced with this current situation, a National AIDS policy is to be finalized very soon. Non-governmental organizations (NGOs) have been working successfully in Bangladesh. Therefore, cooperation of NAC and NGOs would be more efficacious to prevent AIDS among the CSWs. The most immediate thing to do is to promote regular and correct use of condoms in the brothels. NGOs can promote this through medical care of the CSWs. As clients are the decision makers about condom use, they also should be targeted by mass media, posters and leaflets in and around the brothel. Repatriate individuals, frequent travelers, and emigrant workers should also be included in the AIDS prevention program, i.e., mass media campaign; poster leaflets in health check-up centers for emigrant workers, travel agencies from where travel tickets are bought, and the airport; and, if possible, counseling service for departing travelers.

In addition there are some illegal brothels in the main seaports of Bangladesh which entertain overseas sailors. They could also be a source of HIV infection. Specific AIDS awareness program should also target them. Also there are floating CSWs in major cities in Bangladesh. They work in the city slum areas and some of the residential hotels in big cities. AIDS awareness materials like posters and leaflets should also be targeted at all of the residential hotels. However, posters and leaflets are not suitable for slum areas because about $75 \%$ CSWs are illiterate. Local leaders and young enthusiastic persons should be mobilized for AIDS awareness in these slum areas. Slum areas are also the nests of many injecting drug users (IDUs) in Bangladesh. Therefore, it is more efficacious to involve both CSWs and IDUs in AIDS awareness program at one setting. NGOs can contribute to this aspect by using their experience.
Some CSWs of Bangladeshi origin are working in Calcutta in India where HIV is highly prevalent ${ }^{9}$. So special measures should be taken to check the entry of those CSWs into Bangladeshi brothels.

In conclusion, a consensus should be established among the brothel authorities and CSWs about the regular use of condom, which could be realized by the joint efforts of NAC and the NGOs. Periodic medical check-up program and screening for STDs and HIV of the CSWs are also mandatory for the prevention of HIV transmission.

\section{ACKNOWLEDGEMENT}

This study was financially supported by a grant from National AIDS Committee (NAC), Bangladesh.

\section{REFERENCES}

1. Report of the National AIDS Prevention and Control Project (NAPCP), Bangladesh 1997.

2. HIV/AIDS: figure and trends. UNAIDS March 1996.

3. HIV/AIDS in South-East -Asia an update. Regional office paper for South-East Asia. World Health Organization 1995 pp:1-9.

4. The Bangladesh Observer. Al-helal Printing and Publishing Co. LTD. 22nd May 1997

5. Boland M. Overview of perinatally transmitted HIV infection. Nurs-Clin-North-Am 1996 Mar; 31 (1): 15564.

6. Soda K. Extent of the HIV pandemic. Tenth International Conference on AIDS. Yokohama, Japan. 1994 ; p-29.

7. Hossain SMI, Bhuiya I, Streatfield K. Professional blood donors, blood banks and risk of STDs and HIV/AIDS in Bangladesh. South and South-East -Asia Regional Working Papers 1996, No 6:1-91.

8. Rahman M, Shimu TA, Shimbo T, Fukui T. AIDS awareness among the overseas job seekers from Bangladesh(abstract). J Epidemiol 1998;8(1) supplement.; 77

9. Chakraborty AK, Jana S, Das A, Khodakevich L, 